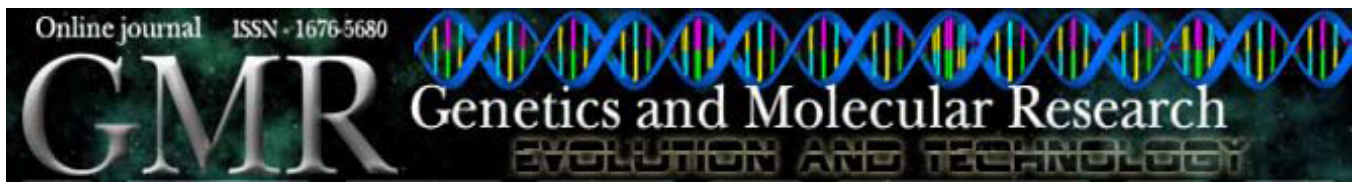

\title{
Genotype and phenotype correlations in diabetic patients in Uruguay
}

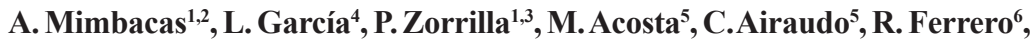 \\ A. Pena ${ }^{5}$, B. Simonelli ${ }^{5}$, E. Soto ${ }^{6}$, G. Vitarella ${ }^{7}$, J. Fernandez ${ }^{5}$ and G. Javiel ${ }^{7}$ \\ ${ }^{1}$ Unit of Human Genetics, Genetics Department, \\ Instituto de Investigaciones Biológicas Clemente Estable, Montevideo, Uruguay \\ ${ }^{2}$ Genetic Evolution Section, Biology Department, \\ UDELAR, Montevideo, Uruguay \\ ${ }^{3}$ Centre National de Genotypage, Evry, France \\ ${ }^{4}$ Molecular Virology Laboratory, Center of Nuclear Research, \\ UDELAR, Montevideo, Uruguay \\ ${ }^{5}$ Endocrinology Polyclinic, Pasteur Hospital Ministerio de Salud Pública, \\ Montevideo, Uruguay \\ ${ }^{6}$ Medical Outpatient Clinic of Centro de Asistencia del \\ "Sindicato Médico del Uruguay", Montevideo, Uruguay \\ ${ }^{7}$ Diabetologic Service of the Center of Assistance for the \\ Centro de Asistencia del "Sindicato Médico del Uruguay", Montevideo, Uruguay
}

Corresponding author: A. Mimbacas

E-mail: abmg@iibce.edu.uy

Genet. Mol. Res. 8 (4): 1352-1358 (2009)

Received August 3, 2009

Accepted September 17, 2009

Published November 10, 2009

\begin{abstract}
To differentiate among different types of diabetes is becoming an increasingly challenging task. We investigated whether the patient's genetic profile is useful to identify the particular type of diabetes, to determine the corresponding hyperglycemia pathogenesis and treat accordingly. Three hundred and thirty-eight diabetic patients, diagnosed according to American Diabetes Association criteria, were recruited from 2004 to 2008 in diabetes health reference centers. We analyzed the major gene for type 1 diabetes susceptibility (HLA DQ/DR). In order to improve our understanding of the pathogenesis of the resulting hyperglycemia and to implement a more adequate treatment for the patients, we reclassified our sample ac-
\end{abstract}


cording to the presence or absence of the genetic markers. We found that a higher percentage of people than expected have immunological disease, independent of their phenotype, with a relative risk of 4.62 (95\% confidence interval). This methodology allowed us to establish an association between the genotype and its resulting phenotype. We found significant differences; the phenotypic classification did not reflect immunological disease based on genotype. Moreover, when we examined markers, body mass index and age of onset, we found that many people have an intermediate phenotype between type 1 and type 2 . This genetic data can help provide an accurate definition of the disease and would therefore provide the physician a better possibility of providing adequate treatment.

Key words: Antibodies; Diabetes mellitus; HLA

\section{INTRODUCTION}

Diabetes mellitus is a group of metabolic diseases characterized by hyperglycemia resulting from defects in insulin secretion, insulin action, or both. The classification of this entity has always been very difficult.

One hundred and fifty years ago, Reyboso observed glucosuria, a condition induced by ether anesthesia, in which glucose is discharged in the urine, and in 1877 Claude Bernard described hyperglycemia during hemorrhagic shock (Wright et al., 1974). Today, it is well known that any type of acute illness or injury can result in insulin resistance, glucose intolerance, and hyperglycemia, a constellation termed "diabetes of injury" (Libman and Becker, 2003; Van den Bergue, 2004). The classification of diabetes has gone through several attempts to compile the many different disease entities included in the term diabetes under a single classification criterion (Alberti and Zimmet, 1998; Pozzilli and Di Mario, 2001; Anonymous, 2004; Tuomi, 2005; Pozzilli and Buzzetti, 2007; Pozzilli et al., 2007). Over the past decade, numerous reports have appeared describing adults and adolescent children, usually from minority groups, presenting ketoacidosis with absence of islet cell antibodies and with characteristics of type 2 diabetes, such as obesity, acanthosis nigricans and/or significant family history of diabetes (Pinhas-Hamiel et al., 1997; Pinhas-Hamiel and Zeitler, 1999). Epidemiological data suggest that both type 1 and type 2 diabetes coexist in type 1 diabetes families (Libman et al., 2001). Present diagnosis diabetes criteria (Anonymous, 2004) applied to classified patients have shown clear differences between type 1 and type 2 diabetes. However, this classification does not fully explain the differences in the evolution of the disease or the different responses to treatment among individuals. This suggests the existence of specific genetic factors influencing disease evolution and response to treatment.

Several years ago, we focused our investigation on HLA genes associated with diabetes. Our studies (Mimbacas et al., 2003, 2004) were done both by case-control and parent-cases design; we found a very high frequency of specific alleles (DQB1*0201, DQB1*0302, DR3, DR4) in our population. Though the associated alleles were the same as those of the Caucasian population, we found that almost all of the patients had associated DR3 and DR4 alleles. The same was found for HLA DQ: -DQB1*0201, *0302. Based on our research experience with diabetes patients, it is very difficult to classify the patients in one of the major diabetes categories (type 1 or type 2). Moreover, patients do not always have a good response to treatment. For these reasons, 
we were interested in the hypothesis that the genotype influences the phenotype of this disease.

We were interested in determining whether genetic profile is useful to provide more accurate information for the clinician and the patient, not only to know the particular type of diabetes, but also so that they can understand the hyperglycemia pathogenesis and to treat it more effectively.

\section{MATERIAL AND METHODS}

We began to study a dynamic cohort in 2004, defined by diabetes according to American Diabetes Association (Anonymous, 2004) criteria. We analyzed the relationship between genotype and phenotype in this Uruguayan diabetic population. Based on the $8 \%$ prevalence in our country (Ferrero and García, 2005), we estimated the baseline sample to be 304 individuals (with $95 \%$ confidence); this was calculated using the statistics program SPSS (https://www.spss. com). Allowing for possible dropouts and technical problems during follow-up, we recruited 338 individuals selected at random among unrelated patients from the major reference medical health institutions attending diabetes (Luzardo et al., 2002); the inclusion of public and private health centers allowed us to stratify the population according to socio-economic categories. We chose this strategy because our country has a unique admixed population composed of three ethnic groups (Cardoso et al., 2004; Gascue et al., 2005; Mimbacas et al., 2003, 2004, 2007).

All subjects were interviewed by medical doctors and answered a standardized protocol. This included age at diabetes onset, the presence or absence of acute symptoms before diagnosis (polydipsia, polyuria, unintentional loss of weight, and ketosis), weight and height at diagnosis in accordance to the calculated body mass index (BMI), blood pressure and family history of diabetes, and presence or onset of diabetes-related chronic diseases (comorbidity). We collected data on blood glucose, total cholesterol, HDL cholesterol, LDL and triglyceride levels, and glycated hemoglobin (HbAlc). All patients were supervised every three months by the same team of physicians (diabetologists, endocrinologists and cardiologist). The study was approved by the local Research Ethics Committees. Informed consent was provided by each subject for all procedures undertaken. All patients gave written consent and the project was approved by the Ministry of Public Health.

We collected $5 \mathrm{~mL}$ of peripheral blood from each subject to obtain DNA and serum to test for genetic markers. In a previous paper, we defined the HLA DQ and DR susceptibility alleles and genotypes for the Uruguayan diabetic population (Mimbacas et al., 2003, 2004). Based on that information, we analyzed the HLA genes considered to be associated with type 1 diabetes; we genotyped the alleles DR3 and DR4 for HLA DR, and alleles HLA DQB*0201 and HLA DQB1*0302 for HLA DQ. Patients having any tumor process or a secondary type of diabetes were excluded from the study.

\section{Epidemiological study}

Three hundred and thirty-eight patients were analyzed for genetic markers. We established the cohort groups as diabetes type 1 and diabetes type 2 according to ADA criteria. The HLA DR alleles were genotyped by PCR, using allele-specific amplifications, as described in the European Consortium for IDDM Genetic Studies (Nerup and Pociot, 2001; Rich et al., 2006). The HLA DQB was analyzed with the commercial kit LIRAS ${ }^{\mathrm{TM}}$ for LiPA-HLA (Innogenetics Inc.). In our analysis of the relation between phenotype and genotype, we obtained unexpected results; as a consequence, we re-defined the sub-cohort groups, taking into con- 
sideration the presence of absence of genetic markers strongly associated with type 1 disease (HLA DQ/DR). To determine if genetic markers are associated with autoimmune disease, we used the statistical program Epi-Info 6.0 (Epi 6, 2008, http://www.cica.es/epiinfo/). To test for immunological disease we examined the samples for antibodies (Turner et al., 1997).

\section{RESULTS}

During a period of five years, we examined a dynamic cohort of clinical history of 338 patients, with $89.9 \%$ follow-up. We excluded 34 individuals at the end of this study (final $\mathrm{N}=304$ ): three individuals died, one patient began a tumor process, we did not obtain PCR products in two patients, and 28 withdrew (i.e., patients who left the health center or did not regularly return for exams). Initially, we classified the patients into two groups: type 1 diabetes (142 individuals) and type 2 diabetes (162 individuals), according to American Diabetes Association criteria. The clinical characteristics of the two cohorts are shown in Table 1.

Table 1. Characteristics of the population studied.
\begin{tabular}{lcc}
\hline & Type 1 diabetes & Type 2 diabetes \\
\hline Age at onset (years) & $13.27 \pm 12.72$ & $48.95 \pm 10.08$ \\
HbAlc $(\%)$ & $10.06 \pm 2.35$ & $7.89 \pm 1.59$ \\
Cholesterol (mg/dL) & $186.00 \pm 50.35$ & $203.37 \pm 42.43$ \\
HDL (mg/dL) & $57.19 \pm 16.60$ & $51.89 \pm 27.78$ \\
LDL (mg/dL) & $105.93 \pm 42.36$ & $122.27 \pm 63.00$ \\
Triglycerides (mg/dL) & $109.48 \pm 71.78$ & $189.14 \pm 125.28$ \\
Body mass index $\left(\mathrm{kg} / \mathrm{m}^{2}\right)$ & $20.02 \pm 4.21$ & $2.35 \pm 5.10$ \\
\hline
\end{tabular}

Data are reported as means $\pm \mathrm{SD}$ on diabetes groups defined according to American Diabetes Association (Anonymous, 2004) criteria.

In the diabetic sample, $34.5 \%$ were $0-15$ years old, $6.91 \%$ were $15-25$ years old and $58.6 \%$ were more than 25 years old. The sub-cohorts were $8.8 \pm 11.9$ years old ( $0-35$ years) for type 1 diabetics and $49.2 \pm 11.2$ years old for type 2 diabetics. These two groups reported $12.4 \pm 9.0$ and $20.5 \pm 19.2$ years of evolution, respectively. All individuals were genotyped for HLA. The genetic results are shown in Figure 1.

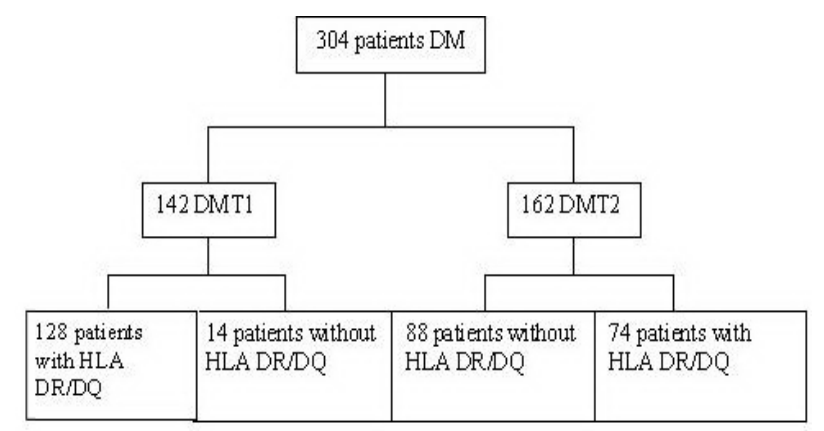

Figure 1. Genetic analysis of the sample. $\mathrm{N}=304$ was the baseline sample. The patients were classified into two groups: type 1 diabetes (DMT1; 142 individuals) and type 2 diabetes mellitus (DMT2, 162 individuals). According to HLA DQB/DR diabetes susceptibility, we reclassified our cohort groups into four sub-groups. 
We made a new division of the sample according to the genetic results and reclassified our cohort groups into four sub-groups according to HLA DQB/DR diabetes susceptibility (Figure 2): a) 128 patients classified as type 1 diabetes who were positive for HLA; b) 14 patients classified as type 1 but negative for HLA markers; c) 88 patients classified as type 2 who were negative for HLA; d) 74 patients classified as type 2 who were positive for HLA.

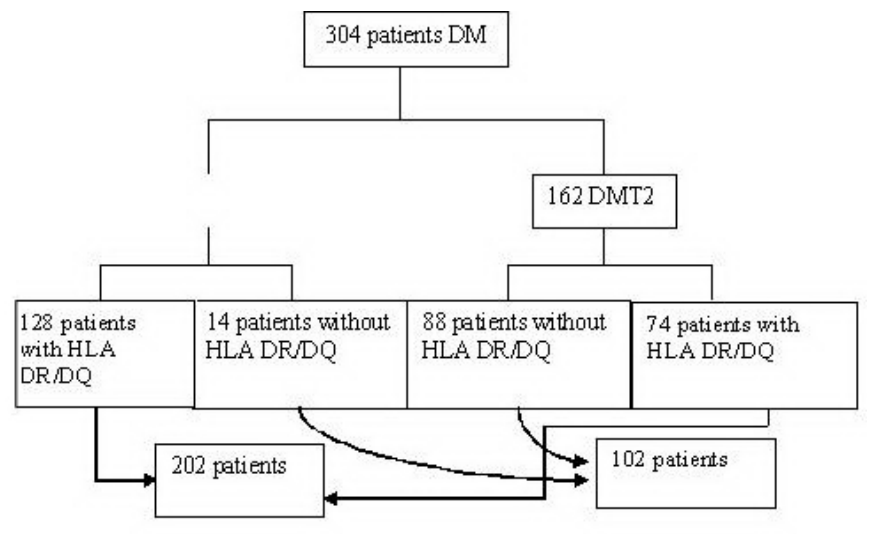

Figure 2. HLA distribution without considering the previous classification of type 1 and type 2 diabetes mellitus (DMT2).

A 2 x 2-contingency table was used to analyze the relationship between genotype (HLA positive or negative) and phenotype (presence or absence of DT1). We obtained a relative risk $(\mathrm{RR})=4.62$ and a confidence interval $(\mathrm{CI})=2.81<\mathrm{RR}<7.59$. The chi-square value was 65.12 (Yates corrected) with $\mathrm{P}<0.001$.

\section{DISCUSSION}

For the clinician and the patient, it could be more important to understand the pathogenesis of the hyperglycemia and to decide on the most efficient treatment than to label the particular type of diabetes. A specific diagnosis based on genetic and immunological markers help clinicians determine treatment; it would also help screen for associated abnormalities, help in the detection of possible future outcomes, and be useful for researchers and epidemiologists interested in the impact, etiology and pathogenesis of diabetes (Libman and Becker, 2003). At present, differentiating between types of diabetes is challenging. We believe that it is important to analyze diabetes from a genetic point of view; this is supported by the results that we obtained here.

The effect of genetic variables on diabetes has been studied for several decades, but only a few consistent risk factors have been identified to date. The entire scale candidate gene studies published so far on diabetes have not performed a combined analysis of both types of diabetes and not used admixed populations as Uruguayan ones. We consider that the Uruguayan population can provide useful information for epidemiological studies (Cardoso et al., 2004; Gascue et al., 2005; Mimbacas et al., 2003, 2004, 2007). 
We estimated the effect of genetic variation and its relationship with phenotype in a dynamic diabetes cohort. We selected a major gene (HLA DQ-DR gene) to identify type 1 diabetes as an immunological marker disease in our cohort study.

When we based our study on the American Diabetes Association classification, we found that the people identified as having type 1 diabetes presented HLA susceptibility, but $9.9 \%$ of the cases $(14 / 142)$ lacked this marker, which is an expected percentage based on the American Diabetes Association classification. However, when we classified the patients according to BMI and age at onset, $93.2 \%$ typically presented diabetes type 1 , and $6.3 \%$ were older than 35 years at onset and were of normal weight to slightly obese. It was possible that these patients presented type 1 diabetes or latent autoimmune adult diabetes. To confirm this, we need to determine which of the patients present the short variable in the VNTR Insulin gene. The other patients $(8 / 128)$ possibly present a new manifestation of diabetes called double diabetes, for the following reasons: one of them was a child diagnosed as diabetic at 7 years old; he presented acanthosis nigricans, with a $\mathrm{BMI}=31 \mathrm{~kg} / \mathrm{m}^{2}$, but he was positive for antibodies and HLA. The other patient was older than 35 years and his BMI $>25 \mathrm{~kg} / \mathrm{m}^{2}$. There were no HLA markers in 14 patients classified as type 1 . Eleven of them had a BMI $<25 \mathrm{~kg} / \mathrm{m}^{2}$ and age of diagnosis $<25$ years. These patients presented positive antibodies but at low values. We suppose that these people had diabetes associated with genes other than HLA, such as the insulin receptor gene or protein tyrosine phosphatase non-receptor type 22 gene (PTPN22). Currently, we are investigating these possibilities and analyzing the patients with their physicians in order to investigate differences compared with classic type 1 diabetes.

When we analyzed the people diagnosed as type 2, we found unexpected results, the genetic background of $46 \%$ of them was associated with immunological disease. This is more than expected (10-15\%; Anonymous, 2004). All these patients presented antibodies (Turner et al., 1997). The patients with onset at $>35$ years possibly could be latent autoimmune diabetes of adults, according to Zimmet et al. (1999). Another possibility is that these patients could have double diabetes. We need to analyze these patients in more detail, but we think that because of our high admixture population characteristics, it is more feasible that they have double diabetes (Libman and Becker, 2003; Pozzilli and Buzzetti, 2007; Pozzilli et al., 2007).

In order to improve our understanding of the pathogenesis of the hyperglycemia and to implement a more adequate treatment for the patients, we reclassified our sample according to the presence or absence of the genetic markers. This methodology allowed us to establish an association between the genotype and its resulting phenotype. We found significant differences, which means that the phenotypic classification does not reflect immunologic disease based on genotype. Moreover, when we examined markers, body mass index and age at onset, we found that it is possible that many people have an intermediate phenotype between type 1 and type 2 .

\section{ACKNOWLEDGMENTS}

Thanks to Cecile Julier PHD, Centre National de Genotypage (CNG), Evry, France, for receiving MSc. Cecilia Gascue and Lic. Pilar Zorrilla in her laboratory and for supporting the HLA DR studies. We also thank her for contributions in the revision of this paper. Research

partially supported by PDT "Programa de Desarrollo Tecnológico", PEDECIBA (Postgrade Program), Uruguay, Laboratorio Xanofi-Aventis, Uruguay, Innogenetics Lda. 


\section{REFERENCES}

Alberti KG and Zimmet PZ (1998). Definition, diagnosis and classification of diabetes mellitus and its complications. Part 1: diagnosis and classification of diabetes mellitus provisional report of a WHO consultation. Diabet. Med. 15: 539-553. Anonymous (2004). Diagnosis and classification of diabetes mellitus. Diabetes Care 27 (Suppl 1): S5-S10.

Cardoso H, Crispino B, Mimbacas A and Cardoso ME (2004). A low prevalence of cystic fibrosis in Uruguayans of mainly European descent. Genet. Mol. Res. 3: 258-263.

Epi 6 (2008). Available at [http://www.cica.es/epiinfo/]. Accessed July 15, 2008.

Ferrero R and Garcia T (2005). Survey on the prevalence of diabetes in Uruguay. [Encuesta de prevalencia de la diabetes en Uruguay. Primera fase: Montevideo]. Arch. Med. Intern. 27: 1-12.

Gascue C, Mimbacas A, Sans M, Gallino JP, et al. (2005). Frequencies of the four major Amerindian mtDNA haplogroups in the population of Montevideo, Uruguay. Hum. Biol. 77: 873-878.

Libman IM and Becker DJ (2003). Coexistence of type 1 and type 2 diabetes mellitus: "double" diabetes? Pediatr. Diabetes 4: 110-113.

Libman IM, Pietropaolo M, Arslanian S, LaPorte R, et al. (2001). Changing phenotype: Are more youngsters with IDDM obese at onset? Diabetologia 44: a257.

Luzardo G, Aznarez I, Crispino B, Mimbacas A, et al. (2002). Cystic fibrosis in Uruguay. Genet. Mol. Res. 1: 32-38.

Mimbacas A, Perez-Bravo F, Hidalgo PC, Javiel G, et al. (2003). Association between diabetes type 1 and DQB1 alleles in a case-control study conducted in Montevideo, Uruguay. Genet. Mol. Res. 2: 29-35.

Mimbacas A, Perez-Bravo F, Santos JL, Pisciottano C, et al. (2004). The association between HLA DQ genetic polymorphism and type 1 diabetes in a case-parent study conducted in an admixed population. Eur. J. Epidemiol. 19: 931-934.

Mimbacas A, Trujillo J, Gascue C, Javiel G, et al. (2007). Prevalence of vitamin D receptor gene polymorphism in a Uruguayan population and its relation to type 1 diabetes mellitus. Genet. Mol. Res. 6: 534-542.

Nerup J and Pociot F (2001). A genome wide scan for type 1-diabetes susceptibility in Scandinavian families: identification of new loci with evidence of interactions. Am. J. Hum. Genet. 69: 1301-1313.

Pinhas-Hamiel O and Zeitler P (1999). The importance of a name. N. Engl. J. Med. 340: 1418-1421.

Pinhas-Hamiel O, Dolan LM and Zeitler PS (1997). Diabetic ketoacidosis among obese African-American adolescents with NIDDM. Diabetes Care 20: 484-486.

Pozzilli P and Di Mario U (2001). Autoimmune diabetes not requiring insulin at diagnosis (latent autoimmune diabetes of the adult): definition, characterization, and potential prevention. Diabetes Care 24: 1460-1467.

Pozzilli P and Buzzetti R (2007). A new expression of diabetes: double diabetes. Trends Endocrinol. Metab. 18: 52-57.

Pozzilli P, Guglielmi C, Pronina E and Petraikina E (2007). Double or hybrid diabetes associated with an increase in type 1 and type 2 diabetes in children and youths. Pediatr. Diabetes 8 (Suppl 9): 88-95.

Rich SS, Concannon P, Erlich H, Julier C, et al. (2006). The type 1 diabetes genetics consortium. Ann. N. Y. Acad. Sci. 1079: $1-8$.

Tuomi T (2005). Type 1 and type 2 diabetes: what do they have in common? Diabetes 54 (Suppl 2): S40-S45.

Turner R, Stratton I, Horton V, Manley S, et al. (1997). UKPDS 25: autoantibodies to islet-cell cytoplasm and glutamic acid decarboxylase for prediction of insulin requirement in type 2 diabetes. UK Prospective Diabetes Study Group. Lancet 350: 1288-1293.

Van den Berghe G (2004). How does blood glucose control with insulin save lives in intensive care? J. Clin. Invest. 114: 1187-1195.

Wright PD, Henderson K and Johnston ID (1974). Glucose utilization and insulin secretion during surgery in man. $B r . J$. Surg. 61: 5-8.

Zimmet P, Turner R, McCarty D, Rowley M, et al. (1999). Crucial points at diagnosis. Type 2 diabetes or slow type 1 diabetes. Diabetes Care 22 (Suppl 2): B59-B64. 